\title{
Implementation of fuzzy logic control algorithm in embedded microcomputers for dedicated application
}

\author{
G.S. Nhivekar ${ }^{1}$, S.S. Nirmale ${ }^{1}$, R.R. Mudholker ${ }^{1}$ \\ ${ }^{1 *}$ Department of Electronics, Shivaji University, Kolhapur, INDIA \\ *Corresponding Author: e-mail: gonioelect@gmail.com, Tel +91-9970222316
}

\begin{abstract}
Fuzzy logic control algorithm solves problems that are difficult to address with traditional control techniques. This paper describes an implementation of fuzzy logic control algorithm using inexpensive hardware as well as how to use fuzzy logic to tackle a specific control problem without any special software tools. As a case study, hardware implementation of fuzzy control algorithm for online temperature control system is demonstrated using 8-bit microcontroller. The hardware implementation followed by software approach has been discussed. Real time result of fuzzy logic temperature control system is also presented.
\end{abstract}

Keywords: AVR, Fuzzy, Microcontrollers, embedded.

\section{Introduction}

Fuzzy techniques have been successfully used in control in several fields, and Engineers and Researchers are today considering fuzzy logic algorithms in order to implement intelligent functions in Embedded Systems. Fuzzy logic controller delivers improved performance over a classical controller has been testified by many researchers. (Nour et al., 2007). Combination of a fuzzy inference system and PID is the better approach to control highly non-linear dynamics process. (Kleanthis et al., 2006).In the past few decades or so, the main area of success with fuzzy logic was in industry control. The application of fuzzy logic allows us to specify the relationship between sensor inputs and actuator outputs using "If...Then..." type of linguistic rules. A fuzzy logic algorithm would be able to translate or interpolate these rules into a nonlinear mapping between sensor input signals and actuator outputs for feedback control (Cox, 1998). Fuzzy logic makes it easy for a human designer to fine tune a control system through trial and success approach. Together with some other approaches such as Artificial Neural Networks, Genetic Algorithm etc., Fuzzy logic considered to be a useful tool for non-model based control system design.

This paper discusses an implementation of a fuzzy inference unit and algorithms for fuzzification, rule evaluation and defuzzification of a fuzzy closed loop control system. Techniques to generate optimized fuzzy based real time code in C, with short development time have being demonstrated using the Atmel AVR Atmega8 microcontroller. We have constructed a standalone fuzzy logic controller (FLC) for an online temperature control system. The performance of the Atmega 8 for fuzzy-based control is studied.

\section{Fuzzy Temperature Controller Hardware Design}

FLC consist of temperature control manifested in the form of fuzzy relation between the present temperature to be controlled and the desired set-point temperature (Driankow et.al,1996). The fundamental nature of Fuzzy Control Algorithm is the conditional statement between fuzzy input variable (present furnace temperature) and fuzzy output variable (heater current). A temperature control system consisted of a sensor, actuator, and microcontroller. Fig.1 shows the actual block diagram of fuzzy logic temperature controller.

Fuzzy Logic has been employed to control temperature by varying ON-time of heater. The actual temperature is read and compared with the corresponding to set-point temperature. The error-count is used to trigger the Fuzzy Inference process. This develops an overall power for heater control that maintains the temperature of furnace to the set value. 


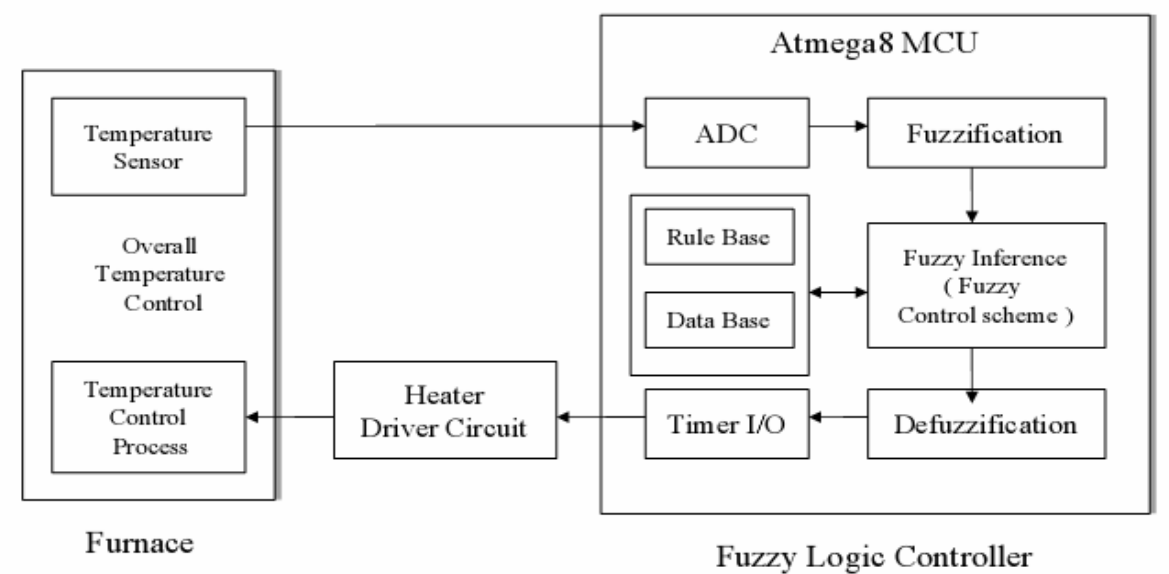

Figure 1. Block diagram of fuzzy logic temperature controller

Temperature is being measured using an integrated circuit temperature sensor LM35, which have an analog output voltage. The output voltage of sensor is linearly proportional to temperature with a gradient of $10 \mathrm{mV} /{ }^{\circ} \mathrm{C}$ and able to operate in the range $-55^{\circ} \mathrm{C}$ to $+150^{\circ} \mathrm{C}$ with an accuracy of $\pm 0.5^{\circ} \mathrm{C}$. The analog output of sensor is given to on-chip Analog to Digital Converter (ADC) of microcontroller. ADC converts an analog voltage into corresponding digital word, which is processed to get the actual physical parameter and then displayed on the LCD module interfaced to the ports of microcontroller. Circuit diagram of the fuzzy logic temperature control system is depicted in Fig. 2.

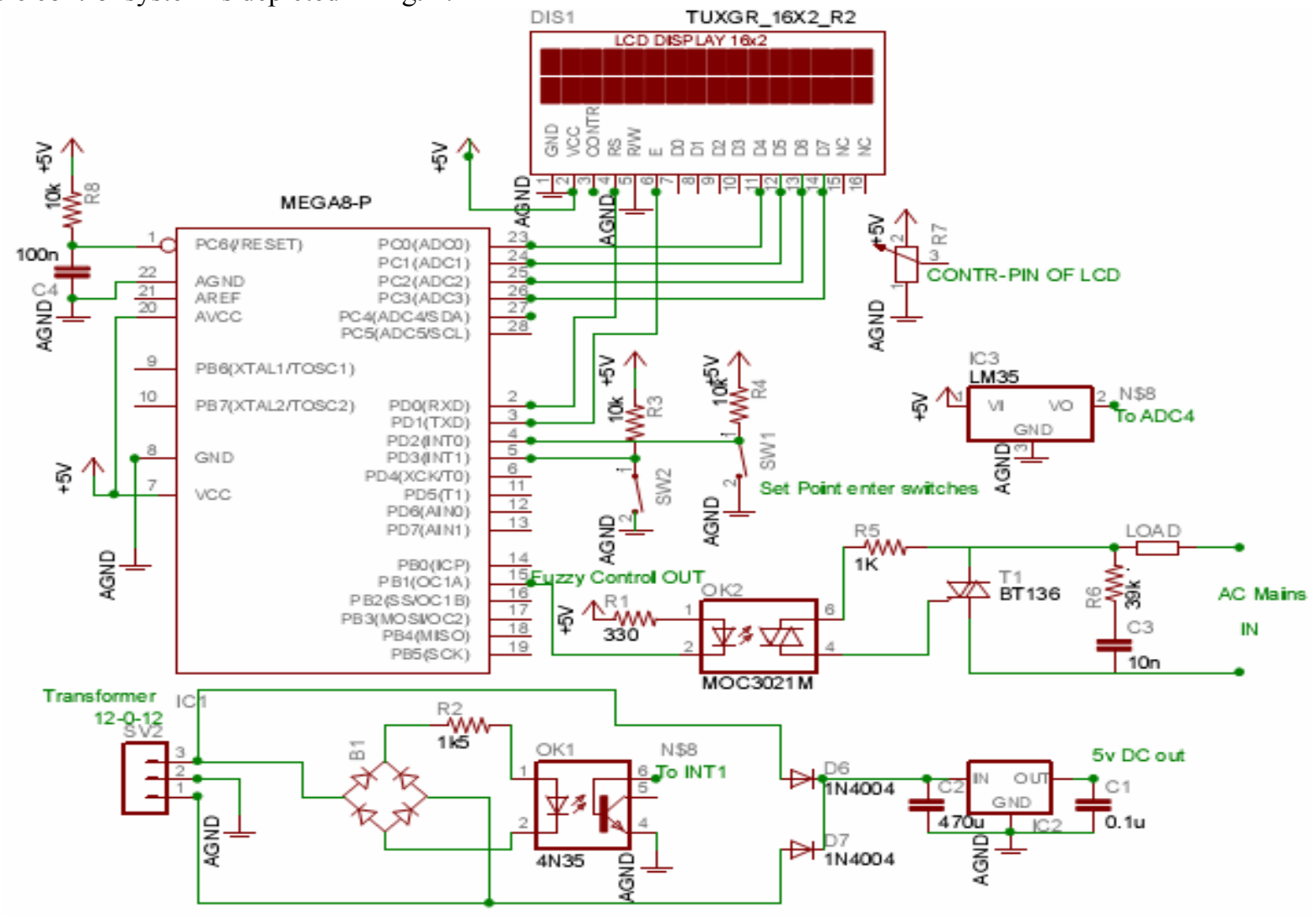

Figure 2. Circuit diagram of the fuzzy logic temperature control system

2.1 Microcontroller Unit: The system circuit diagram shown in Fig.2 has been designed around the ATMEL AVR Atmega8 microcontroller. The microcontroller's on-chip peripherals like programmable I/O port, Timer and External Rest, RC-oscillator, EEPROM, Power On Reset (POR) are being used to lower the cost and to increase the efficiency and reliability. This makes AVR microcontroller a better choice for such embedded systems. MCU uses calibrated $8 \mathrm{MHz}$ internal RC oscillator for system clock 
2.3 Zero crossing detector: In order to fire Triac exactly at the zero point of the AC cycle, zero crossing detector has been employed. Zero crossing detector generates pulses for every zero crossing of the input AC signal. These pulses are fed to the microcontroller interrupt pin through the opto-coupler. The opto-coupler is used for the isolation of the high voltage AC to the low voltage DC supply at the microcontroller side.

2.4 Heater actuator: The power control device used here is a triac BT136 being least expensive power switch to operate directly on the $110 / 240 \mathrm{~V}$ mains. It can withstand a maximum load current typically $5 \mathrm{~A}$. Phase angle control technique is employed to control the load power (Philips Semiconductors, Application note). The output power is controlled by the phase delay of the triac drive. This delay is referred to the zero crossing of the line voltage detected by zero crossing detector circuit. The control output from microcontroller port pin is given to opto-coupler MOC3031M to trigger the triac. The triac is driven in quadrants QII and QIII with $60 \mathrm{~mA}$ gate current with $100 \mathrm{uS}$ pulse width. This pulse width is sufficiently long to insure the triac gets latched at the end of the pulse.

\section{Software Implementation of Fuzzy Logic Temperature Controller}

3.1 Fuzzification of Input: Fuzzification is the process of changing a real scalar value into a fuzzy value .Fuzzy variables are used to translate real values into fuzzy values. The possible values of a fuzzy variable are not numbers but so-called "linguistic terms". The input linguistic variables for Fuzzy Logic Temperature Controller (FLTC) express linguistically the difference between the set point and the measured and calculated signals from a temperature sensor. Input to FLTC is Error= (Set point-Temperature sensed). Triangular and trapezoidal membership functions are used to fuzzify the input. For fuzzifier program, it is necessary to determine the range of fuzzy variables related to the crisp inputs. Difference Temperature sensed is restricted to positive values. The following fuzzy sets are used: $\mathrm{NEG}=$ negative, $\mathrm{SNEG}=$ small negative, $\mathrm{ZERO}=$ zero, $\mathrm{SPOZ}=$ small positive, $\mathrm{POZ}=$ positive. Table 1 shows the Membership function for input linguistic variable.

Table 1. Input linguistic variables

\begin{tabular}{|c|c|c|}
\hline Sr No & $\begin{array}{c}\text { Crisp Input Range } \\
\text { (Error=Set point }- \text { Current Temperature) }\end{array}$ & Fuzzy Variable Name \\
\hline 1 & -15 to -50 & NEG \\
\hline 2 & 0 to -30 & SNEG \\
\hline 3 & -15 to +15 & ZERO \\
\hline 4 & 0 to 30 & SPOZ \\
\hline 5 & 15 to 50 & POZ \\
\hline
\end{tabular}

To include the linguistic variable positive (POZ) to a microcontroller, translation of the graphical representation into meaningful code is needed. The following C code fragment gives one example of how to do this. The subprogram "fuzzify_MF" receive the crisp input value, range of fuzzy variables for membership function and returns a degree of membership, scaled between zero and one, indicating the degree to which a given input temperature can be POZ. Similarly, degree for each input membership function is calculated. Fig. 3 shows the graphical representation of the membership function for input linguistic variable.

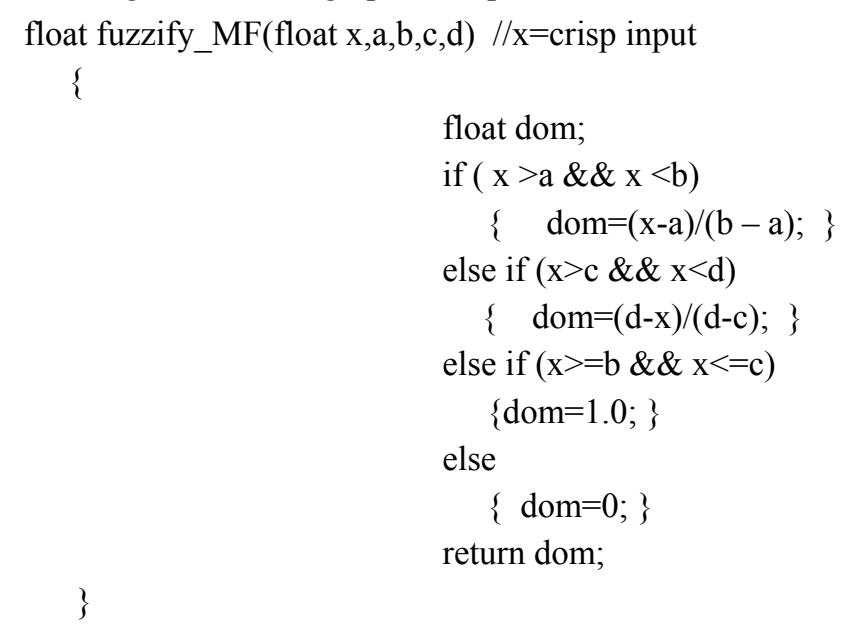




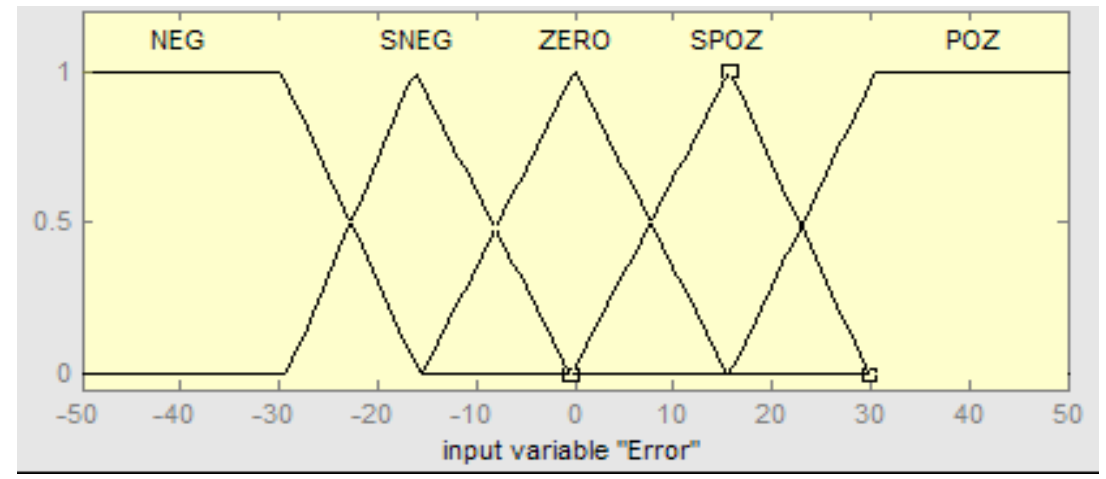

Figure 3. Graphical representation of membership function for input linguistic variable

3.2 Fuzzy Membership Functions for Outputs: The output linguistic variables express linguistically the applied values to the FLTC actuators for temperature control. The output linguistic variables are shown in the Table 2. Present study considered typically one output variable, which is a firing angle. It is necessary to assign fuzzy memberships to output variable, similar to the input variable. The fuzzy sets used for firing angle are as follows: $\mathrm{Z}=$ zero, $\mathrm{L}=$ large, $\mathrm{M}=$ medium, $\mathrm{H}=\mathrm{high}, \mathrm{VH}=$ very high. Fig. 4 shows the graphical representation of the membership function for output linguistic variable.

Table 2. Output linguistic variables

\begin{tabular}{|c|c|c|c|}
\hline Sr No & $\begin{array}{c}\text { Fuzzy variable range for output } \\
\text { Phase angle }(\Theta)\end{array}$ & $\begin{array}{c}\text { Corresponding } \\
\text { MCU Timer Count }\end{array}$ & Fuzzy variable name \\
\hline 1 & 10 to 50 & 64935 to 63735 & $\mathrm{Z}$ \\
\hline 2 & 10 to 90 & 64935 to 60535 & $\mathrm{~L}$ \\
\hline 3 & 50 to 130 & 63735 to 57735 & $\mathrm{M}$ \\
\hline 4 & 90 to 170 & 60535 to 64533 & H \\
\hline 5 & 130 to 170 & 57735 to 64533 & VH \\
\hline
\end{tabular}

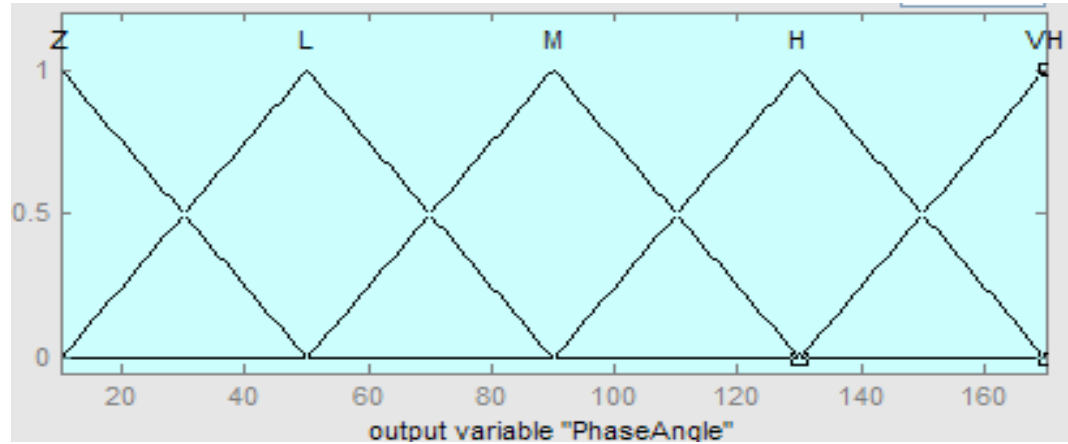

Figure 4. Graphical representation of membership function for output linguistic variable

3.3 Knowledge Representation and Rule block: Once the current values of the input variables are fuzzified, the fuzzy controller continues with the phase of "making decisions," or deciding what actions to take to bring the temperature to its set-point value. The criteria for this action are minimum time and minimum temperature oscillation. The rule blocks contain the control policy of a Fuzzy Control System. The rules 'IF' part describes the situation, for which the rules are designed. The 'THEN' part describes the response of the fuzzy system in this situation. The control policy of heater is structurally formulated in terms of fuzzy rules as shown in table 3.

Table 3. Fuzzy rules

\begin{tabular}{|c|c|c|}
\hline Rule No. & IF the Error is & THEN firing angle is \\
\hline 1 & NEG & VH \\
\hline 2 & SNEG & H \\
\hline 3 & ZERO & M \\
\hline 4 & SPOZ & L \\
\hline 5 & POZ & Z \\
\hline
\end{tabular}


These fuzzy rules can be flexibly modified whenever needed is achieved by a fragment of $\mathrm{C}$ program as given below structfuzzy_rule

\{

struct MF_lable *input1;

struct MF_lable *output;

float f;

;

struct fuzzy_rule R[Num_rules];

For example, rule1 "If error is NEG then firing angle is Z" can be defined as follows-

$\mathrm{R}[1]$.input $1=\& N E G$;

$\mathrm{R}[1]$. output $=\& Z$;

$\mathrm{R}[1] . \mathrm{f}=0$; //initializing

This process is iterative based on trial and success approach for entire rule base.

3.4 Defuzzification: The result of the defuzzification has to be a numeric value that determines the firing angle of the Triac used to drive the heater. There are many ways to perform defuzzification; in this case, crisp output is obtained by weighted average defuzzification technique described by equation (1).

$$
\text { Defuz }=\frac{\sum_{i=1}^{5} P[i] \times W[i]}{\sum_{i=1}^{5} W[i]} \ldots \text { (1) }
$$

$\mathrm{P}[\mathrm{i}]$ is the peak value of $\mathrm{i}^{\text {th }}$ output membership function. $\mathrm{W}[\mathrm{i}]$ is the weight associated with $\mathrm{i}^{\text {th }}$ rule. The following $\mathrm{C}$ code fragment gives one example of how to convert fuzzy variable to crisp output.

int defuzzify(float W1,W2,W3,W4,W5) //receive Degree of Each Membership function

\{

float SM_DOM;

int OUTPUT ;

SM_DOM $=\mathrm{H} 1+\mathrm{H} 2+\mathrm{H} 3+\mathrm{H} 4+\mathrm{H} 5 ;$ //sum of Degree of Membership function

OUT̄PUT $=((\mathrm{W} 1 * 64935)+(\mathrm{W} 2 * 63735)+(\mathrm{W} 3 * 60535)+(\mathrm{W} 4 * 57735)+(\mathrm{W} 5 * 64533)) /\left(\mathrm{SM} \_\mathrm{DOM}\right)$;

Return (OUTPUT);

\}

The subprogram "defuzzify" receives the degree of each membership function calculated in fuzzification step and returns defuzzified output, which is used to control the firing angle of triac.

\section{Results and Discussion}

The temperatures in the case study are as follows: set temperature $=40^{\circ} \mathrm{C}$; and current temperature $=27^{\circ} \mathrm{C}$. Using data logger device real time readings are collected (Nhivekar et al., 2011) and current temperature versus time graph is plotted as shown in Fig. 5. On the graph it can be observed that after $58 \mathrm{sec}$. temperature set point is achieved and after $62 \mathrm{sec}$. it become steady around $+/-1^{\circ} \mathrm{C}$ of set point. For the low cost Embedded System, the real time result is quite acceptable. Defuzzified result of output phase angle verses input error is shown in Fig. 6.

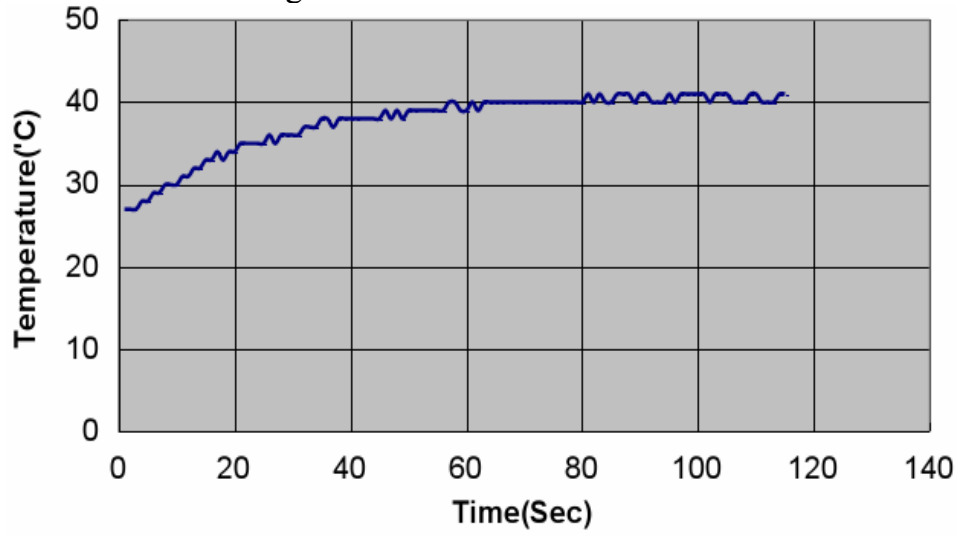

Figure 5. Real time result for current Temperature versus Time 


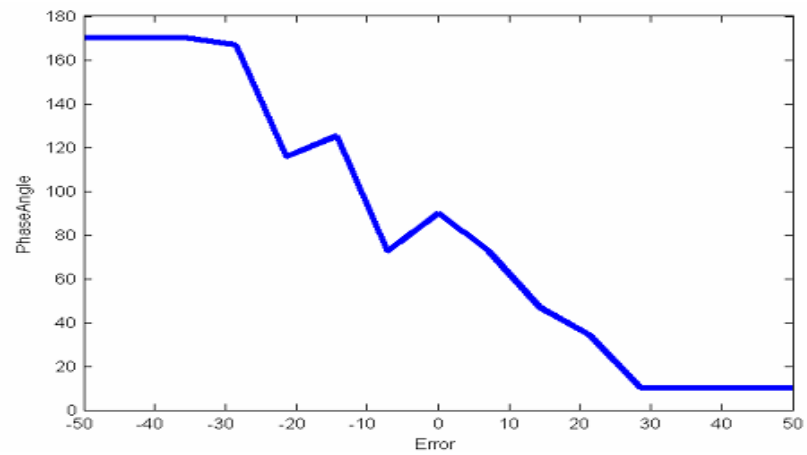

Figure 6. Defuzzified Output phase angle verses Input error

The FLTC system program after initializing the all-peripheral calls a heater-driving program and loads an initial heater control count corresponding to the room temperature, Fig. 7 show the flowchart of system program behavior.

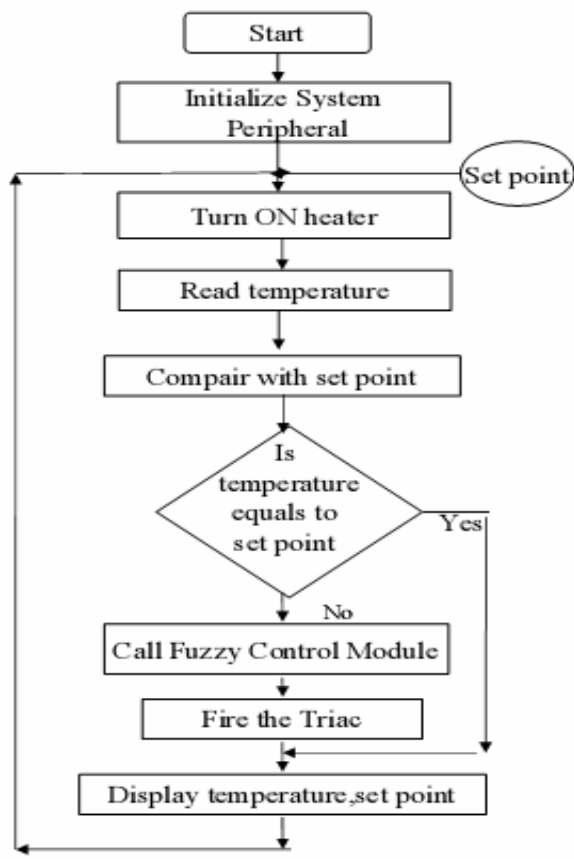

Figure 7. System flowchart

The comparison with the defuzzified count corresponding to the set-point fires the rule and accordingly phase delay of the triac drive (firing angle) gets adjust until the set-point temperature is attained. At this stage, defuzzified microcontroller timer counts corresponding to the phase delay of the triac drive is evaluated and the heater power is controlled to maintain the temperature constant. Microcontroller On chip, 16-bit timer is used to adjust the phase delay of the triac .The temperature is displayed and the process of temperature control continues. Table 4 shows the some performance parameters of FLTC system namely Rise time, Settling time, Steady-state error, Algorithm Execution time and memory used to implement the FLTC system on AVR atmega8 microcontroller.

Table 4. Some performance parameters for FLTC system

\begin{tabular}{|l|l|}
\hline Rise time & $58 \mathrm{sec}$. \\
\hline Settling time & $62 \mathrm{sec}$. \\
\hline Steady-state Error & $+/-1^{\circ} \mathrm{C}$ \\
\hline Execution time $=0.6 \mathrm{mSec}$ & $\begin{array}{l}\text { Total program without LCD } \\
\text { (FLA+ADC+PWM etc.) }\end{array}$ \\
\hline Execution time $=9.4 \mathrm{mSec}$ & $\begin{array}{l}\text { Total program with LCD in 4bit mode } \\
\text { (FLA+ADC+PWM+LCD etc.) }\end{array}$ \\
\hline Total code size & 2665 words $(65.0 \%)$ \\
\hline Free memory block & 1431 words $(35 \%)$ \\
\hline
\end{tabular}




\section{Conclusions}

The fuzzy temperature controller is designed and implemented in 8-bit AVR microcontroller without using any special software tool. Unlike some fuzzy controllers with hundreds, or even thousands, of rules running on computer systems, a unique FLC using a small number of rules and simple implementation is demonstrated to solve a temperature control problem with unknown dynamics or variable time delays commonly found in industry. Also the final hardware is stand-alone system rather than a PC (personal computer/laptop computer) based system that takes control decision based on special software tools running on it and hence the design approach presented in this paper minimizes the total cost of hardware and software design. The control result can be improved by resizing the fuzzy sets and finer tuning for the membership functions.

\section{References}

Nour M.I.H, Ooi J. and Chan K.Y., 2007. "Fuzzy logic control vs. conventional PID control of an inverted pendulum robot", Proceedings of 2007 ICIAS International Conference on Intelligent and Advanced Systems, pp.209-214.

Kleanthis N., Costas N., and Christos S., 2006. "A comparison of classical, neural and fuzzy control for an underwater vehicle", Proceedings of $7^{\text {th }}$ WSEAS international conference on Neural Networks, pp.61-66.

Cox E., 1998.The fuzzy systems handbook, Second Edition, Academic press limited London.

Driankow D., Hellendoorn H.and Reinfrank M., 1996. An Introduction to Fuzzy Control, Narosa Publishing House, New Delhi.

Philips Semiconductors Application note, 1994 "Power Control with Thyristors and Triacs" [online]. Available at: http://www.nxp.com/documents/application_note/APPCHP6.pdf.

Lee S.H., Li Y.F. and Kapila V., 2004. "Development of a Matlab-Based Graphical User Interface for PIC Microcontroller Projects", Proceedings of the American Society of Engineering Education Conference, Salt Lake City, UT, Session 2220.

Mudholkar R. R., Sawant S. R., 2002. "Fuzzy logic build estimation (FLTBE)", Trans Indust Electron, IEEE, Vol.49, No.1, pp.264-267.

Lee S.H., Panda A., 2007. "Development of a Matlab Data Acquisition and Control Toolbox for PIC Microcontrollers", Proceedings of 2007 ASEE American society for engineering education Conference, Louisville, Southeastern Section, April 1-3.

Wong P.H., Kapila V. and Lee S.H., 2006. "Two-Tank Liquid Level Control Using a Basic Stamp Microcontroller and a Matlab Based Data Acquisition and Control Toolbox", Proceedings of the American Society of Engineering Education Conference, Chicago, IL, Session 3520.

Darly Sukumar, Vanaja Ranjan and Benjamin Justus Rabi, 2010. "FLC Based Adjustable Speed Drives for Power Quality Enhancement", Serbian journal of electrical engineering, Vol.7, No.2, pp.217-229.

Pranav Kumar Asthana, 2010. "Power supply system for AC coaches", Advances in Applied Science Research, Vol.1, No.2, pp. 84-91.

Shahanaz Ayub, J.P.Saini, 2010. "Fusion beats extraction from ECG using neural network based soft computing techniques", Advances in Applied Science Research, Vol.1, No.2, pp.76-83.

Ofoefule, Akuzuo U., Nwankwo, Joseph I., Ibeto and Cynthia N., 2010. "Biogas Production from Paper Waste and its blend with Cow dung", Advances in Applied Science Research, Vol.1, No.2, pp.1-8.

Nhivekar G.S., Mudholkar R.R., 2011. "Data Logger and Remote Monitoring System for Multiple Parameter Measurement Applications", Journal of Electrical and Electronics Engineering, Vol. 4, No.1, pp.139-142.

Ionescu F., Haszier F., 1996. "Comparison between classical and fuzzy-controller for electrohydraulic axes", International Symposium on Neuro-Fuzzy Systems, pp.155-160.

Burgos O.T., Hizon, J.R.E. and Sison L.G., 2004. "Comparison of classical and fuzzy control in active mass damping of a flexible structure using acceleration feedback", proceding of TENCON-2004 IEEE Conference, Vol. 4, pp.645-648.

Yi Fu, Li. H. and Kaye, M.E., 2010. "Hardware/Software Codesign for a Fuzzy Autonomous Road-Following System", Proceedings of IEEE System, Man and Cybernetics Society, Vol.40, No.6, pp. 690- 696.

Musa O. Abdalla ,Tagreed M. Al-Jarrah,2011. "Fuzzy Logic Control of an Electrical Traction Elevator", Jordan Journal of Mechanical and Industrial Engineering, Vol.5, No.1, pp. 97- 106.

HuaYun Yu, DaBin Zhang, 2010. "Design of Fuzzy Logic Controllers Based on Evolvable Hardware Platform", $4^{\text {th }}$ International Conference on Genetic and Evolutionary Computing (ICGEC), pp.864- 867.

Jian Qiao, Naiding Yang, Jie Gao,2011. "Two-Stage Fuzzy Logic Controller for Signalized Intersection”, Proceedings of IEEE System, Man and Cybernetics Society, Vol.41, No.1, pp. 178-184.

Chekireda F., Larbesa C., Rekiouab D. and Haddadc F., 2011. "Implementation of a MPPT fuzzy controller for photovoltaic systems on FPGA circuit”, Energy Procedia Elsevier, Vol.6, pp. 541-549.

Biographical notes

Mr.Nhivekar G.S. received Master degree in Electronics science with Embedded System specialized from Shivaji University Kolhapur, India in 2008. Presently he is a research fellow in the Department of Electronics, Shivaji University Kolhapur, India. His research area is fuzzy hardware techniques and control applications. 
Mr.S.S.Nirmale received Master degree in Electronics science with Embedded System specialized from Shivaji University Kolhapur, India in 2004. Presently he is a research fellow in the Department of Electronics, Shivaji University Kolhapur, India. His research area is neural fuzzy and control applications.

Dr. R.R.Mudholker is a Associate Professor in the Department of Electronics, Shivaji University Kolhapur, India. He has more than 20 years of experience in teaching and research. His current area of research includes Embedded fuzzy, Process Control, Neural Networks, and Artificial intelligence. He has published more than thirty papers in referred international journals. He has also presented research articles in national and international conferences. He is currently dealing with few projects sponsored by government of India.

Received June 2011

Accepted July 2011

Final acceptance in revised form July 2011 